\title{
Relative impacts of global changes and regional watershed changes on the inorganic carbon balance of the Chesapeake Bay
}

Pierre St-Laurent ${ }^{1}$, MARJorie A. M. Friedrichs ${ }^{1}$, RAYMOND G. NAJJAR ${ }^{2}$, ELIZABETH H. SHADWICK ${ }^{3}$, HANQIN TIAN ${ }^{4}$, YUANZHI YAO ${ }^{4}$, EDWARD G. STETS ${ }^{5}$

${ }^{1}$ Virginia Institute of Marine Science, William \& Mary, Gloucester Pt, VA (pst-laurent@vims.edu, marjy@vims.edu)

${ }^{2}$ The Pennsylvania State University, University Park, PA

${ }^{3}$ CSIRO, Hobart, TAS, AU

${ }^{4}$ Auburn University, Auburn, AL

${ }^{5}$ USGS, Mounds View, MN

The Chesapeake Bay is a large coastal plain estuary that has experienced considerable anthropogenic change over the past century. At the regional scale, land-use change has doubled the nutrient input from rivers and led to an increase in riverine carbon and alkalinity. The Bay has also experienced global changes, including the rise of atmospheric temperature and $\mathrm{CO}_{2}$. Here we seek to understand the relative impact of regional and global changes on the inorganic carbon balance of the Bay between the early 1900's and the early 2000's. We use a linked land-estuarine-ocean modeling system that includes both inorganic and organic $\mathrm{C}$ and $\mathrm{N}$ cycling. Sensitivity experiments isolate the effects of changes in: (1) atmospheric $\mathrm{CO}_{2}$, (2) temperature, (3) riverine nitrogen loading and (4) riverine $\mathrm{C}$ and alkalinity loading. Specifically, we find that over the past century global changes have increased ingassing by roughly the same amount $(\sim 30 \mathrm{Gg}-\mathrm{C}$ $\left.\mathrm{yr}^{-1}\right)$ as has the increased riverine loadings. While the former is due primarily to increases in atmospheric $\mathrm{CO}_{2}$, the latter results from increased net ecosystem production that enhances ingassing. Interestingly, these increases in ingassing are partially mitigated by increased temperatures and increased riverine carbon and alkalinity inputs, both of which enhance outgassing. Overall, the Bay has evolved over the century to take up more atmospheric $\mathrm{CO}_{2}$ and produce more organic carbon. These results suggest that over the past century, changes in riverine nutrient loads have played an important role in altering coastal carbon budgets, but that ongoing global changes have also substantially affected coastal carbonate chemistry. 